\title{
SURFACE COVER INFILTRATION INDEX: A SUGGESTED METHOD TO ASSESS INFILTRATION CAPACITY FOR INTRINSIC VULNERABILITY IN KARSTIC AREAS IN ABSENCE OF QUANTITATIVE DATA
}

\author{
Levent Tezcan \& Mehmet Ekmekci
}

\begin{abstract}
Karst is a hydrogeological environment of importance not only for its water resources potential but also for its scenic and economic potential, thereby increasing the intensity of human impact. The uniqueness of karst in this regard stems from its high sensitivity and vulnerability to imposed pressures and its distinctive response to these pressures. Therefore, a clear definition and formulation of the concept of 'intrinsic vulnerability' is essential for the design of vulnerability and/or management criteria of the karstic system as a resource. In this regard, the recharge rate, the amount of water passing through the unsaturated zone into the aquifer, is among the principal attributes of the intrinsic vulnerability. Where data and measurements are available for even large areas, recharge can be evaluated quantitatively on the basis of field measurements and the water balance equation. However, particularly for countries suffering from lack of essential data for a quantitative evaluation of the net recharge rate, the recharge can be estimated using some derived parameters such as the so called 'Surface Cover Infiltration Index' proposed in this paper. The DRASTIC method which is modified by using SCI, soil thickness and precipitation, allows the unique hydrological behavior of karst to be considered by redistributing of the intrinsic vulnerability values on the basis of hydrologic connections between neighboring cells.

Following a detailed description of the SCI index and the modification of DRASTIC method for karst aquifers, a case study carried out to demonstrate this method is presented in this paper whose objective is to discuss and thus elaborate the suggested methodology. The Olimpos National Park area was selected because the great variation in lithology, landuse and topography. It was found that the relative vulnerability may vary particularly in the neighborhood of the highly vulnerable cells covered by carbonate rocks. The methodology was applied using ARC-GIS software. All spatial features used in computations were classified by the appropriate functions built into the software.
\end{abstract}

Keywords: karst, hydrogeology, vulnerability.

\section{Introduction}

Given the exact mathematical expression of the behavior of a physical system and values of all parameters and variables in the required accuracy and precision, response of the system to any change of any component can be estimated with a given uncertainty. However, most natural systems are still far from being described by exact mathematical 
expressions. This is true particularly for hydrogeological systems. Developing mathematical models to simulate natural systems is the primary purpose of researchers and practitioners. However, mathematical models produce meaningful results only if the required data are provided with a certain scale, reliability, accuracy and precision. Because the studied natural hydrogeological systems cover large areas, generating these data generally requires hard, time consuming and costly work. Empirical relations and equations help the hydrogeologist in solving practical problems but at a lower level of accuracy, because they are easier to use. However, they too require some quantitative data generation. Moreover, in most cases empirical relations are site-specific; therefore some constants and parameters should be determined for the application site if one wants to be correct at a certain level. There is still a way out even if the smaller amount of data required by the empirical equations are lacking: parametric system methods also called 'expert systems'. Although the uncertainty inherent to these types of tools is high, they provide the hydrogeologist with rapid and in many cases effective solutions. It is clear that uncertainty increases as the natural system is defined with less mathematics. That is, mathematical expressions are most accurate while expert systems are least accurate (excluding descriptive evaluation based on completely subjective observations). The tools require more knowledge and experience as they contain more uncertainty. Knowledge about the tool itself and the application area together with experience in problem-definition are essential for an effective use of expert systems such as point count system models also known as parameter weighting and rating methods.

Expert systems are the most common tools used for assessing potential of groundwater pollution. This potential pollution is referred to as groundwater/aquifer vulnerability. Two types of vulnerability are defined; intrinsic and specific. Intrinsic vulnerability refers to the properties of the groundwater system only and does not consider a specific contaminant whereas specific vulnerability associates intrinsic vulnerability with a specific contaminant. Methods of assessing intrinsic vulnerability are much more common because specific vulnerability requires some data related to the behavior of that specific contaminant.

DRASTIC is the most common method used in intrinsic vulnerability mapping. In this context, groundwater vulnerability mapping is used as a guide in identifying areas that are more susceptible to groundwater contamination within the mapped area. Scale of data controls the scale of the vulnerability maps. Therefore, accuracy of vulnerability maps are scale dependent. As explained above, the nature of the method necessitates experience in hydrogeology and close familiarity with the site.

Due to the very specific nature of karst aquifers, uncertainty inherent to expert systems like DRASTIC is twofold. Karst is a fragile environment and requires very detailed and careful examination for several aspects but primarily of water input, throughput and output. Some methods such as EPIK and VULK were proposed for karst terrains (Civita, et al, 1991; Doerfliger and Zwahlen, 1995). These methods involve parameters specific to karst but still require improvement, especially for applications in large areas that include both karstic and nonkarstic lithologies. The unique nature of karst involves the effective interconnection between surface and subsurface drainage. In vulnerability mapping, an area having low vulnerability may directly be interconnected with a highly vulnerable karstic area through the input features. 
To the authors, it is reasonable to modify the commonly used DRASTIC method so that it also considers the very specific character of karst instead of proposing new methods. This, subsequently, requires re-designation of DRASTIC parameters in terms of weights and rates. An index for assessment of Surface Cover Infiltration Ability is defined and proposed to be used within DRASTIC method for karstic terrains.

\section{Drastic modified for karst aquifers}

DRASTIC essentially combines the major geologic and hydrogeologic factors that control groundwater movement in a hydrological system (Aller, et al., 1987). The features that it considers are evident in its name: depth to water (D), recharge (R), aquifer media (A), soil media (S), topography (T), impact of vadose zone (I) and hydraulic conductivity of aquifer $(\mathrm{C})$. The weighting and rating technique is applied by numerical ranking of these features which involves weights, ranges and ratings. The most significant factors have weights of 5; the least significant a weight of 1 .

It is clear that karst can be reflected only in terms of aquifer media and conductivity both having a medium weight (3) compared to D (5), I (5), and R (4). On the other hand, in karstic areas, due to the rapid conduit flow which contributes directly to groundwater, the effect of depth to water and thickness is less pronounced. Specific to karst, type of recharge is more significant than the rate of recharge. Similarly, the effect of topography is much more pronounced as the surface runoff may be diverted into subsurface flow path through karstic features. Hence, an additional knowledge and experience in karst hydrogeology is also essential for an effective DRASTIC mapping of karst aquifers. In order to reduce the subjective judgments, the DRASTIC features were re-organized to reflect the specific character of karst aquifers. In this context, depth to water (D), aquifer media (A), hydraulic conductivity (C) and partially the impact of the vadose zone (I) were evaluated within one derived index called the surface cover infiltration ability index (SCI). SCI is derived by overlaying the surface lithology (SL), lineaments (L), drainage density (DD), and karstic features (KF). In the next step, the derived map is matched with the soil cover thickness to convert the SCI to surface cover protectiveness (SCP). Apparently, SCP includes - to a certain degree - the impact of the vadose zone too. The intrinsic vulnerability index (IVI) is obtained by overlaying the rainfall distribution over the area as the potential recharge feature $(\mathrm{R})$. In order to be on the safe side, the areal precipitation map should be prepared using the maximum monthly precipitation records. It should be noted that on the IVI map, vulnerability values are computed independently without considering the hydrogeological conditions in other cells. In contrast, allogenic recharge of karst aquifers indicates that it is essential to consider the hydrologic interrelation among cells in assigning a vulnerability value. For example, a high IVI cell may receive direct contribution by surface runoff from a low IVI cell. It is evident that, for a more effective vulnerability mapping, the IVI should be re-assessed for the low IVI cell so as to reflect this contribution. In other words, the low IVI cell should have a higher IVI and thus should be considered, in effect, as more susceptible to pollution because even though there will be no direct contribution of contaminant to the groundwater directly on this cell, it may transfer the pollutant to a high IVI cell ( a karstic cell with point recharge for instance).

This problem is resolved by re-assessing IVI values by quantifying the interrelation 
among cells. Quantification of hydrologic interrelation among cells is made by defining a travel time index (TTI) which is the measure of contribution of the upstream cells to that located downstream. Calculation of TTI is based on the slope of the surface topography (T). The IVI is redistributed by weighting the rate of contribution. The final map is the RIVI map for areas including also karstic terrains. Obviously all DRASTIC features are used but in different arrangement to reflect the nature of karst.

\section{Surface cover infiltration ability (SCI)}

"Surface Cover Infiltration (SCI) Index" is dependent on some selected lithological, structural, hydrological and morphological factors. The actual infiltration depends upon several meteorological, hydrogeological and topographical parameters, such as the effective rainfall, slope and cover of the terrain, fracture intensity, karstic features, and surface lithology. However, in this descriptive approach, which does not intend to assess the actual infiltration, the term 'infiltration' is used only to define the relative ability of the surface cover to permit the water to seep to the subsurface.

A weighting and rating method is used for assessment of the surface cover infiltration. It is derived from four parameters which are considered to play the major role in giving the unit the ability of permitting the water to seep into the subsurface in natural conditions. These are surface lithology, lineaments, karstic features and drainage density. The method presents a descriptive approach. In the SCI index the area under examination is discretized into a grid of finite square elements (FSE). The size of FSE is dependent on the scale of the map. However, the morphological and hydrogeological structural complexity of the area controls the size of the basic grid. The scale should be selected to allow a reasonable balance between the need of high resolution and the detail of the data available.

\section{Surface Lithology (SL)}

Surface lithology is classified according to either permeability, a function of the medium only, or hydraulic conductivity, a function not only of the porous medium but also of the fluid. Three main classes for the surface lithology are considered in SCI index: Pervious, Semipervious and Impervious. Rating decreases as the permeability of the surface cover decreases (Table 1). Abundant data about the range of values of hydraulic conductivity and permeability are well documented in the literature. The range of values of hydraulic conductivity and permeability that can be used in assigning a rating to the surface lithology, if this specific value is not available for the study area can be found in Bear (1979) or Freeze and Cherry (1979). Permeability of the surface cover and relative ratings are as follows:

\begin{tabular}{ll} 
Hydrogeological Character & Rating \\
\hline Pervious & 2 \\
Semipervious & 1 \\
Impervious & 0 \\
\hline
\end{tabular}

\section{Lineaments $(\mathbf{L})$}

Structural relationships play an important role in the infiltration process as well as regional directions of water circulation. Particularly in karstic areas, the structural rela- 
tionships greatly affect the formation of the aquifer and its evolution. Structural analysis requires a large amount of high quality data which can be collected by areal photographs and surface mapping of the terrain.

The SCI index involves the structural relationship as the lineament density. The term lineament is preferred here to 'fracture' because it is not easy to differentiate these two by remote sensing techniques. However, if definition of fractures is possible the SCI index is more reliable. Moreover, fracture genesis classification (tensile, shear and release) provides a better understanding of the aquifer system. Since the presented approach does not intend to give a numerical figure for the infiltration, the above-mentioned details can be literally considered by the person who makes ratings. The difficulty with this analysis is related to the working scale selected for the specific study area. This difficulty is overcome by applying the 'Jenks' natural break classification' method built into ARC-GIS. Ratings that were assigned to the 3 classes obtained by this technique is given below:

\begin{tabular}{ll} 
Lineament Intensity Class & Rating \\
\hline Low & 1 \\
Medium & 2 \\
High & 3
\end{tabular}

\section{Karstic Features (KF)}

Limestone and dolomite are impervious in their intact form. When they are fractured, their infiltration ability increases and they become more pervious. Fractures enlarged by karstification processes are highly permeable. Karstification produces many specific surficial and subsurface landforms which are extremely important from the standpoint of recharge (infiltration), groundwater circulation, and contaminant transport. With regard to infiltration ability, the approach proposed here considers the karstification in the assessment of the SCI index, by measuring the intensity of the karst depressions in terms of the area covered by the karst depression. The KF values for each grid are assigned on the basis of its existence. In other words, each cell is checked whether it contains a karstic feature or not. The rating for the existence of the KF is:

\begin{tabular}{ll} 
Existence & Rating \\
\hline Yes & 3 \\
No & 0
\end{tabular}

\section{Drainage Density (DD)}

The study of the drainage (river) network on a topographical map, particularly when coupled with the parameters explained above, provides useful hints about the hydrogeological conditions. A lot of useful information for hydrogeological mapping is inherent in the drainage network density. It can be a priori concluded that impervious strata exist beneath the surface cover in areas with dense drainage networks. The drainage network density is measured similar to the lineaments by using Jenks' natural break classification built into ARC-GIS. Characterization of the effect of drainage density and relative ratings is given below: 


\begin{tabular}{ll} 
Drainage Density & Rating \\
\hline None & 4 \\
Low & 3 \\
Medium & 2 \\
High & 1 \\
\hline
\end{tabular}

\section{Calculation of SCI Index Using the Weights of SCI}

The weight of each factor is attributed on the basis of its relative importance to infiltration. The SCI Index calculated using the rating and weight given here is to be used only for comparative rating of the infiltration in the study area under investigation only.

\begin{tabular}{ll} 
Factor & Weight $\%$ \\
\hline 1- Surface Lithology & 40 \\
2- Lineament & 20 \\
3- Karst Features & 25 \\
4- Drainage Density & 15 \\
\hline
\end{tabular}

SCI index is then calculated according to the ratings $\left(\mathrm{R}_{\mathrm{i}}\right)$ and weights $\left(\mathrm{W}_{\mathrm{i}}\right)$ of the 4 factors as follows:

$$
\mathrm{SCI}=\Sigma\left(\mathrm{W}_{\mathrm{i}} \mathrm{xR}\right)(\mathrm{i}=1,4)
$$

The SCI itself is weighted and assigned ratings in order to be used as a feature of the DRASTIC modified for karst areas. The weight of SCI in calculating IVI is 5. The ranges and rates are as follows:

\begin{tabular}{ll} 
SCI & Weight $=5$ \\
\hline Range & Rating \\
\hline Very Low & 1 \\
Low & 3 \\
Medium & 5 \\
High & 7 \\
Very High & 9 \\
\hline
\end{tabular}

\section{Surface cover protectiveness (SCP)}

Based on the fact that the major part of the natural attenuation processes take place in the soil cover, the SCI is combined with the soil media to produce the SCP. However, in calculating IVI, the soil medium (S) is used. The soil medium is defined by thickness in this proposed method. Soil permeability or soil composition can also be considered. However, soil thickness is the most readily available parameter with reasonable accuracy. Moreover, the thickness has the major impact on the natural attenuation processes excluding the alluvial and colluvial covers (soils). Alluvial and colluvial or slope-wash covers are regarded as uncovered surface materials of high conductivity. The weight of soil thickness $(\mathrm{S})$ is 3 . The ranges and rates are as follows: 
Soil Thickness $\quad$ Weight $=3$

\begin{tabular}{ll}
\hline Range & Rating \\
\hline No soil $($ lithozolic) $(0-10 \mathrm{~cm})$ & 10 \\
Thin $(10-20 \mathrm{~cm})$ & 8 \\
Moderately Thick $(20-50 \mathrm{~cm})$ & 5 \\
Thick $(50-90 \mathrm{~cm})$ & 3 \\
Very Thick $(>90 \mathrm{~cm})$ & 1 \\
\hline
\end{tabular}

\section{Precipitation (R)}

Major difficulties and large uncertainty are inherent in the calculation of net recharge particularly in areas with limited meteorological data. Unfortunately, this is the common situation in most developing countries whose meteorological network is poor and inefficient in producing data convenient to calculate net recharge. Combination of the surface cover infiltration ability with precipitation provides a good approximation of potential recharge for vulnerability assessment. It should be noted that the vulnerability map is to be used as a guide in determining which areas are more susceptible to groundwater pollution within the mapped area, which means that it produces a relative map. Therefore an index like SCI can be used together with precipitation to assess the relative susceptibility, and apparently it can not be used for recharge estimates for groundwater potential calculations. Remembering that average values are risky to use in contamination studies, and that the seasonal distribution of precipitation is not even, the period of heavy precipitation should be considered in vulnerability assessment in order to be on the safe side. The precipitation is spatially distributed over the area and classified in 5 categories following the method used in SCI. The weight of precipitation is taken as 1 . This feature can be easily re-defined as potential recharge by subtracting evapotranspiration from precipitation which should also involves the land use map.

The 5 classes are categorized and rated as below:

Precipitation Weight $=1$

\begin{tabular}{ll}
\hline Range & Rating \\
\hline Very High & 8 \\
High & 6 \\
Moderate & 5 \\
Low & 3 \\
Very Low & 1 \\
\hline
\end{tabular}

\section{Intrinsic vulnerability index (IVI)}

Having completed the SCI map, Soil Thickness map and Precipitation map, IVI can be calculated by

$$
\mathrm{IVI}=\mathrm{SCIw} * \mathrm{SCIr}+\mathrm{Sw} * \mathrm{Sr}+\mathrm{Pw} * \mathrm{Pr}
$$

Where, the subscripts $\mathrm{w}$ and $\mathrm{r}$ are the weight and ratings of the feature respectively. As explained above, the IVI map is not the final map because it does not consider the hydrologic interrelations among cells. The IVI values are re-distributed on the basis of interconnection with cells which result in new vulnerability values. The final map is then the Redistributed Intrinsic Vulnerability Index (RIVI) map. 


\section{Redistributed intrinsic vulnerability index (RIVI)}

The need for redistribution of IVI values stems from the fact that a low IVI cell may recharge a high IVI cell. In this case, it is not correct to guide the decision-maker toward that low IVI cell ignoring its connection with the high IVI cell. Therefore, all cells recharging high IVI cells should be defined and evaluated in terms of contribution to high IVI cells. In other words, the drainage areas of each high IVI cell should be defined and the contribution of each cell in the drainage area should be assessed. The IVI value of the contributing cell is increased by its contribution. This is quantified by weighting the contribution in terms of travel time. The travel time is estimated from the concentration time (Tc in hr) of hydrologic basins as defined by Kirpich (1940) on the basis of drainage length ( $\mathrm{L}$ in $\mathrm{m})$ and average slope of the basin $(\mathrm{S})$ :

$$
\mathrm{Tc}=\frac{0.00032 \mathrm{~L}^{0.77}}{\mathrm{~S}^{0.385}}
$$

The Tc is evaluated as the travel time index (TTI) and used in weighting the impact of the contributing low IVI cells on the high IVI cell. For this purpose, the IVI and TTI are categorized and rated as below:

\begin{tabular}{lrrr} 
IVI & \multicolumn{3}{l}{ TTI } \\
\hline Range & Rating & Range & Rating \\
\hline Very High & 5 & Very Slow & 1 \\
High & 4 & Slow & 2 \\
Moderate & 3 & Moderate & 3 \\
Low & 2 & Fast & 4 \\
Very Low & 1 & Very Fast & 5 \\
\hline
\end{tabular}

Redistribution of IVI is achieved by the following calculation:

$$
\operatorname{RIVI}_{\mathrm{i}-1}=\left(\mathrm{IVI}_{\mathrm{i}-1} * \Delta\right)+\mathrm{IVI}_{\mathrm{i}-1}
$$

where

$$
\Delta=\left(\mathrm{IVI}_{\mathrm{i}}-\mathrm{IVI}_{\mathrm{i}-\mathrm{i}}\right)^{*} \frac{\mathrm{rTTI}}{\mathrm{rIVI}_{\mathrm{i}}}
$$

rTTI and rIVI are the ratings of TTI and IVI respectively.

The $\Delta$ is taken as zero when $\mathrm{IVI}_{\mathrm{i}}-\mathrm{IVI}_{\mathrm{i}-1}$ is negative (i.e. where the IVI of the contributing cell is higher than IVI of the receiving cell). In this case the IVI value of the contributing cell should remain the same as it does not increase the pollution potential at the receiving cell. If the difference is positive which implies that the contributing cell has a lower IVI than the receiving cell, then the contributing cell should be regarded as an element increasing the pollution potential for the receiving cell and therefore should be assigned a higher IVI value than its actual IVI. For example, if the IVI of the contributing cell is low $\left(\mathrm{IVI}_{\mathrm{i}-1}\right.$ rate=2) and the travel time index is fast (TTI rate=4) and the IVI of the receiving karstic cell is very high $\left(\mathrm{IVI}_{\mathrm{i}}\right.$ rate=5), then it is clear that the contributing 
cell creates as risk of pollution to the receiving cell and should not be ranked as a lowvulnerability cell. When the IVI re-assessed, the RIVI of the contributing cell is found as $\Delta=(5-4) *(4 / 5)=0.6$

and RIVI $=(2 * 0.6)+2=3.2$, which suggests that the contributing cell which has low IVI in effect should be considered as a moderately to highly vulnerable cell.

\section{Case of Olimpos National Park (Turkey) \\ Definition of the Area}

The coastal area extending between Antalya and Olimpos was selected as the study area to demonstrate the DRASTIC method modified on the basis of SCI. The area includes a great diversity of environmental resources all of which are under pressure from human impacts, although the major part of the area is under protection as a national park by the Ministry of Forestry. The study area is situated on the southwest of the Taurus Mountains, along the western shore of the Gulf of Antalya at the Western Mediterranean Region of Turkey (Fig. 1). The surface area is about $2000 \mathrm{~km}^{2}$. The high mountain range forms the western boundary, whereas the area is bounded by the sea on the east. The elevation of the area ranges from mean sea level up to 2366 meters a.m.s.l (Tahtalidag) within only 10 to $15 \mathrm{~km}$ distance inland from the sea coast. The climate prevailing in the area is of Mediterranean type with dry and hot summers and warm and rainy winters. Precipitation occurs mainly in the form of rain except over the high peaks, where snow cover remains until the end of April. There are only two perennial surface streams, the largest of which is located at the northeastern part of the area to the west of the city of Antalya.

The main aquifers are karstic carbonate rocks of various ages. Geologically the study area lies within the Antalya Complex, which is a part of the southwest Taurid Mountains of the Alpine system. The complex is considered to be an allochthonous assemblage dominated by Mesozoic ophiolithic and sedimentary rocks. It can be subdivided into the following structural units, beginning with the structurally lowest unit: the autochthonous Mesozoic-Cenozoic continental platform rocks of Beydaglari; the Kumluca unit of allochthonous, imbricated, Mesozoic continental margin rocks; the Alakirçay unit of

Fig. 1. Location Map of the Olimpos National Park Area

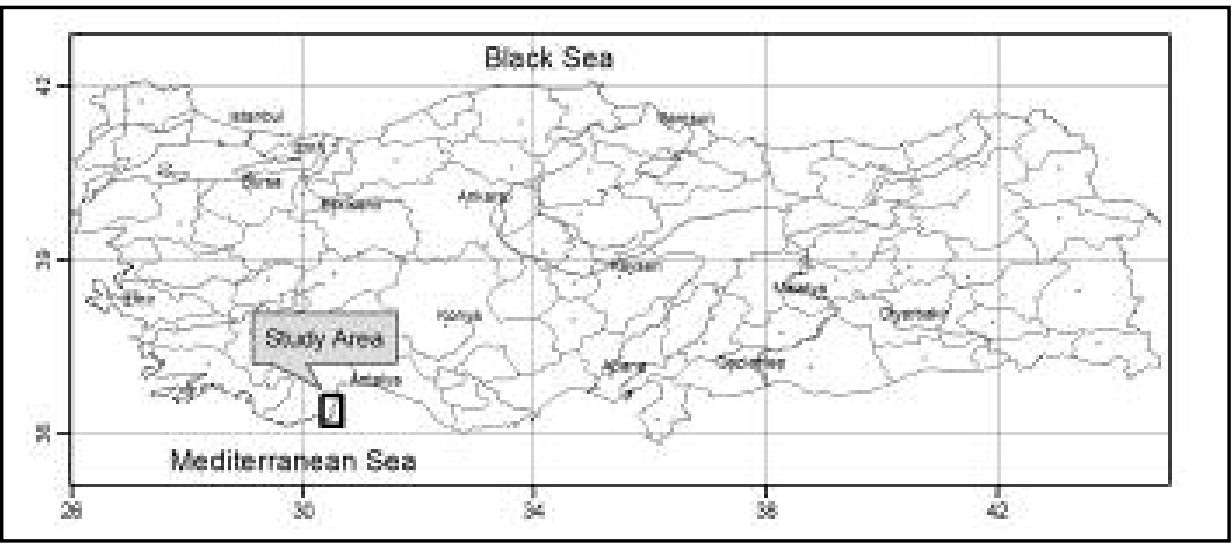




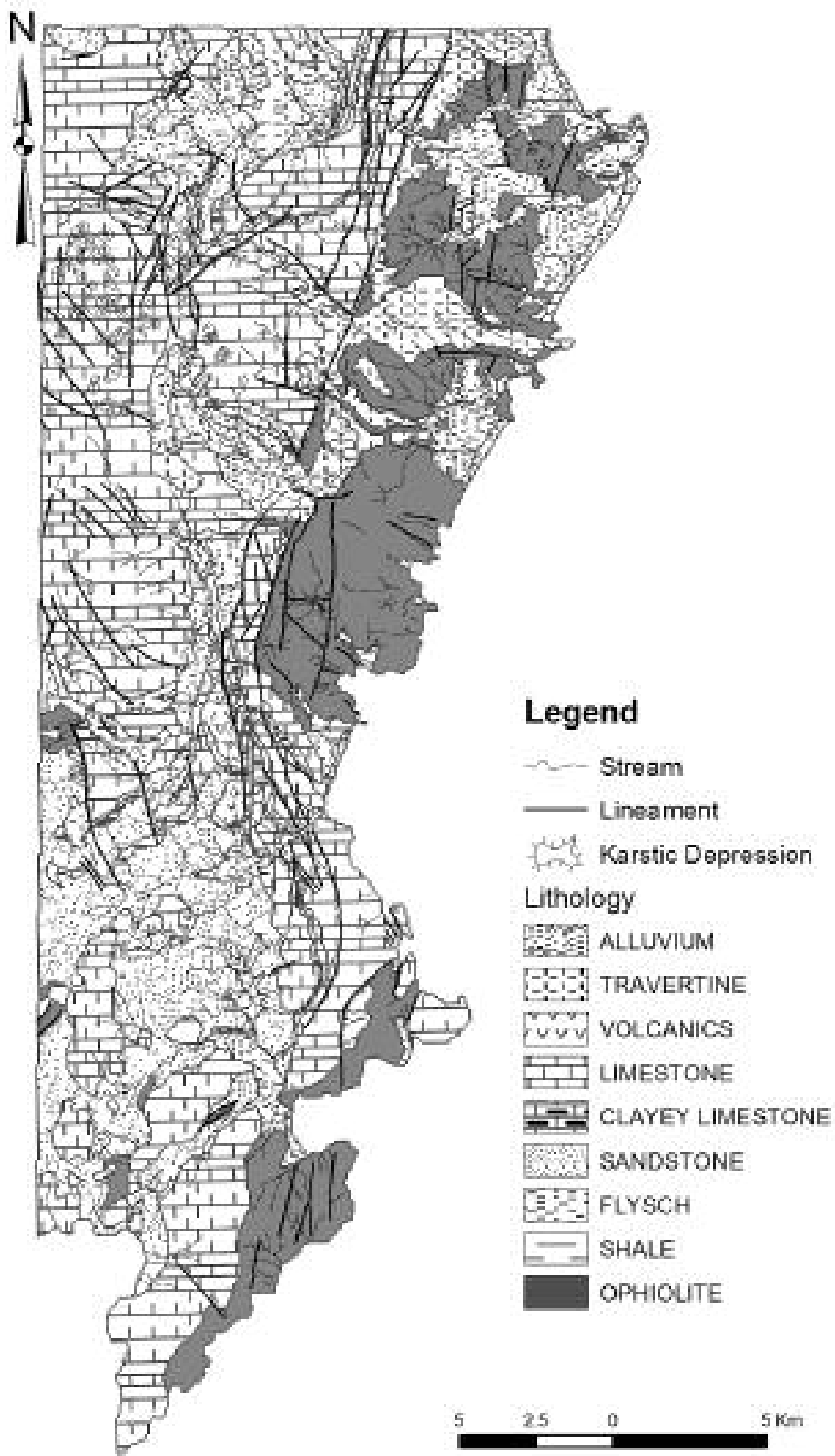

Fig. 2. Simplified Geologic Map of the Olimpos National Park Area 
oceanic and carbonate margin rocks deformed during the latest Cretaceaous by tectonic and gravitational mechanisms into multiple slices interlayered with melange, which includes as a subdivision the Teke-Tahtalidag Unit of exotic Paleozoic-Mesozoic platform rocks and the Tekirova unit, a late Cretaceous partial ophiolite sequence. The geologic map of the study area is given in Fig. 2.

\section{Range and Rating Tables For the Olimpos National Park Area}

Within the Olimpos National Park Area, the features were re-defined to modify the DRASTIC method for karstic terrains. SCI map was derived by ARC-GIS using the layers of geology, lineaments, drainage density and karstic features. Fig. 3 depicts the layers used to derive the SCI map for the Olimpos National Park area. The derived SCI map is also shown in Fig. 3. Following the construction of the SCI map, the soil thickness was digitized from the map of the General Directorate of Rural Affairs and matched with the SCI and precipitation maps to produce the intrinsic vulnerability (IVI) map. The soil thickness map is given in Fig. 4. Precipitation is distributed over the area using the data from three meteorological stations. The data recorded in December were used in generating the areal distribution of precipitation because the heaviest precipitation falls in December (see Fig. 4).

\section{Intrinsic Vulnerability Index (IVI)}

The relative assessment of the intrinsic vulnerability was described in five classes: Very Low, Low, Moderately High, High and Very High. These classes were shown as different colors on the IVI map (see Fig. 4). Very High IVI is predominantly found in the highly fractured and karstified carbonate rocks. Some of these areas are at high elevations and uncovered. In these areas the depth to the water table may be very large. However, the

Fig. 3. Layers Used in SCI Mapping in the Olimpos National Park Area

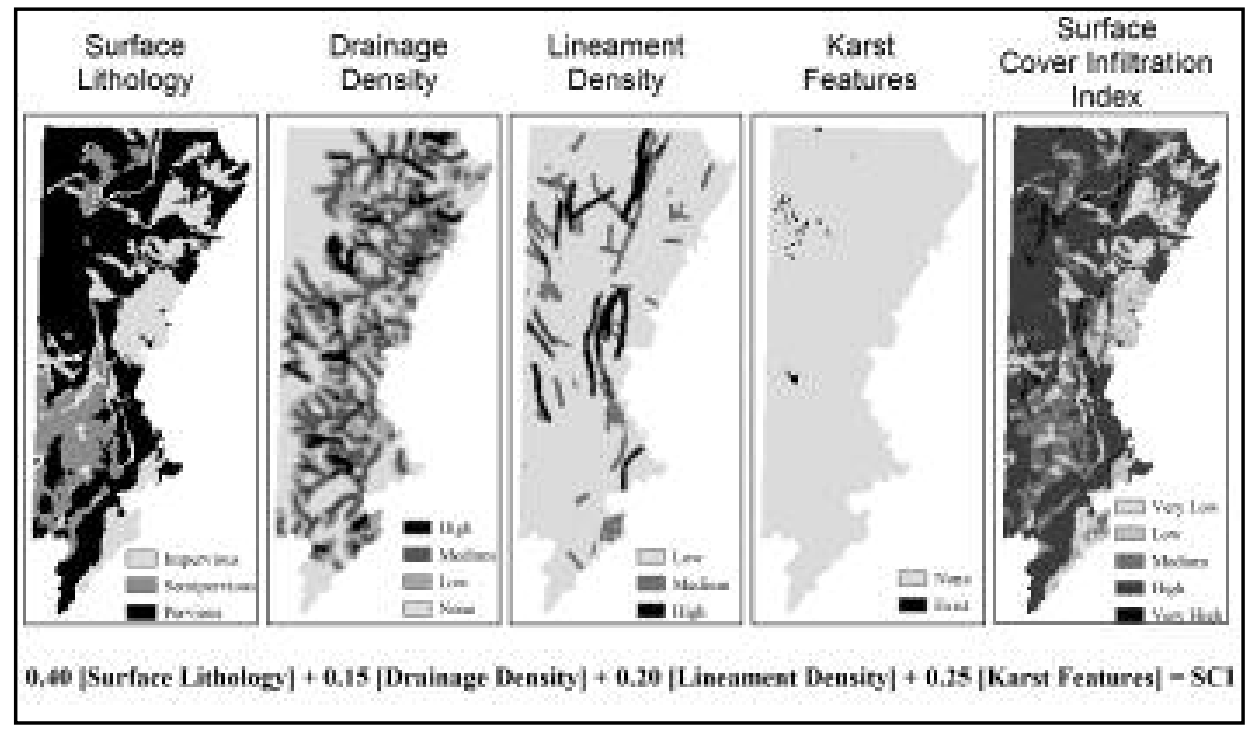




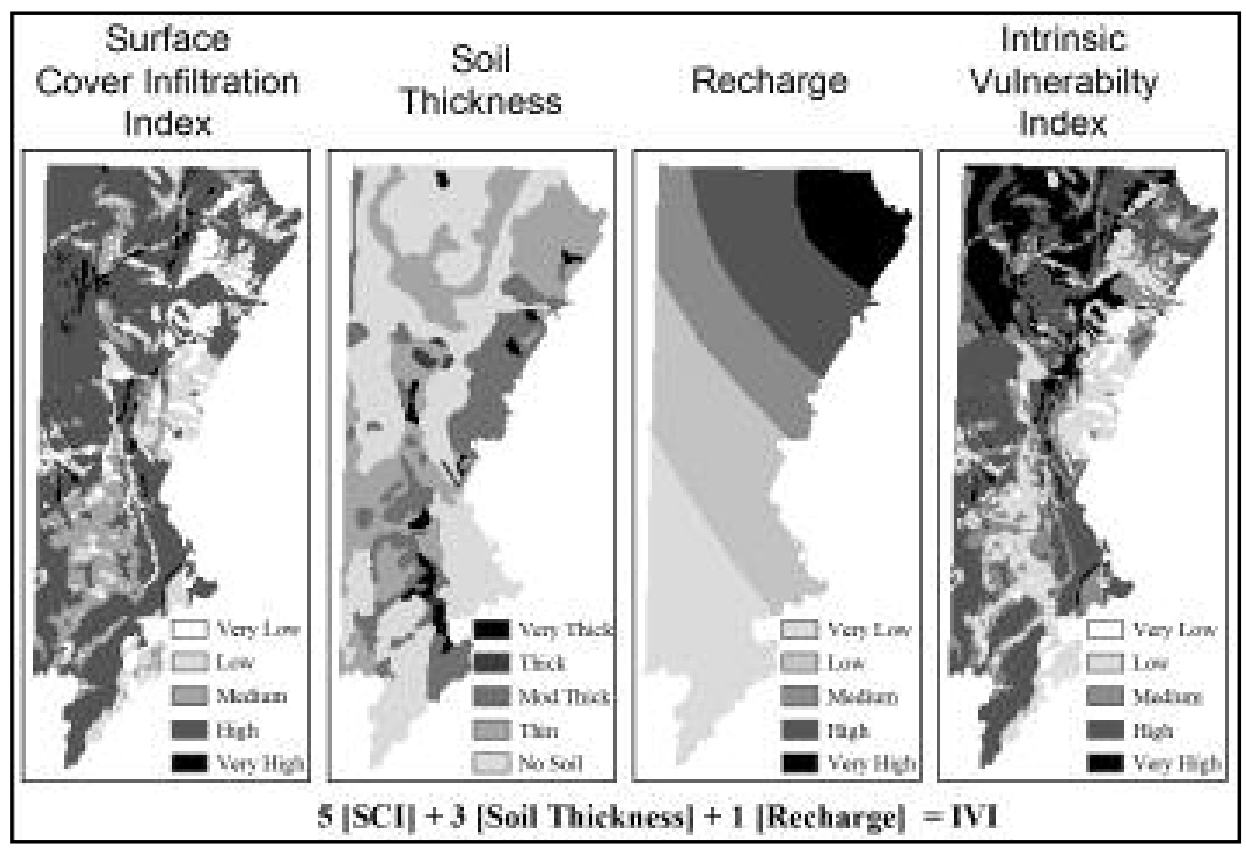

Fig. 4. Layers Used in Intrinsic Vulnerability Mapping in Olimpos National Park Area

intense karstification and lack of surface drainage imply that there is rapid flow to the groundwater. High IVI comprises the largest areas. It is characterized by carbonate rocks that lack extensive karstic features. Thin soil cover may exist in these areas. Moderate IVI is not limited to one geological group. It reflects the importance of the SCI and the soil cover on groundwater vulnerability. Low IVI is characterized by mostly semipervious or covered pervious units. Impervious or covered semipervious units have the very low IVI values. In terms of percentage of the area, the IVI values were distributed as follows:

\begin{tabular}{ll} 
IVI Range & Area $\%$ \\
\hline Very High & 15.80 \\
High & 39.94 \\
Moderate & 19.38 \\
Low & 21.81 \\
Very Low & 3.07 \\
\hline
\end{tabular}

\section{Redistributed Intrinsic Vulnerability Index (RIVI)}

The redistributed intrinsic vulnerability map reflects the importance of hydrologic connections of cells of different IVI values. Assessment of RIVI revealed that the IVI is redistributed to increase the vulnerability value of some less-vulnerable cells, which provides a more realistic relative susceptibility for pollution. After redistribution of IVI, the percentage of the area with very high vulnerability has changed slightly. The result of the redistribution is given below for comparison with the IVI map. The RIVI map is given in Fig. 5. 


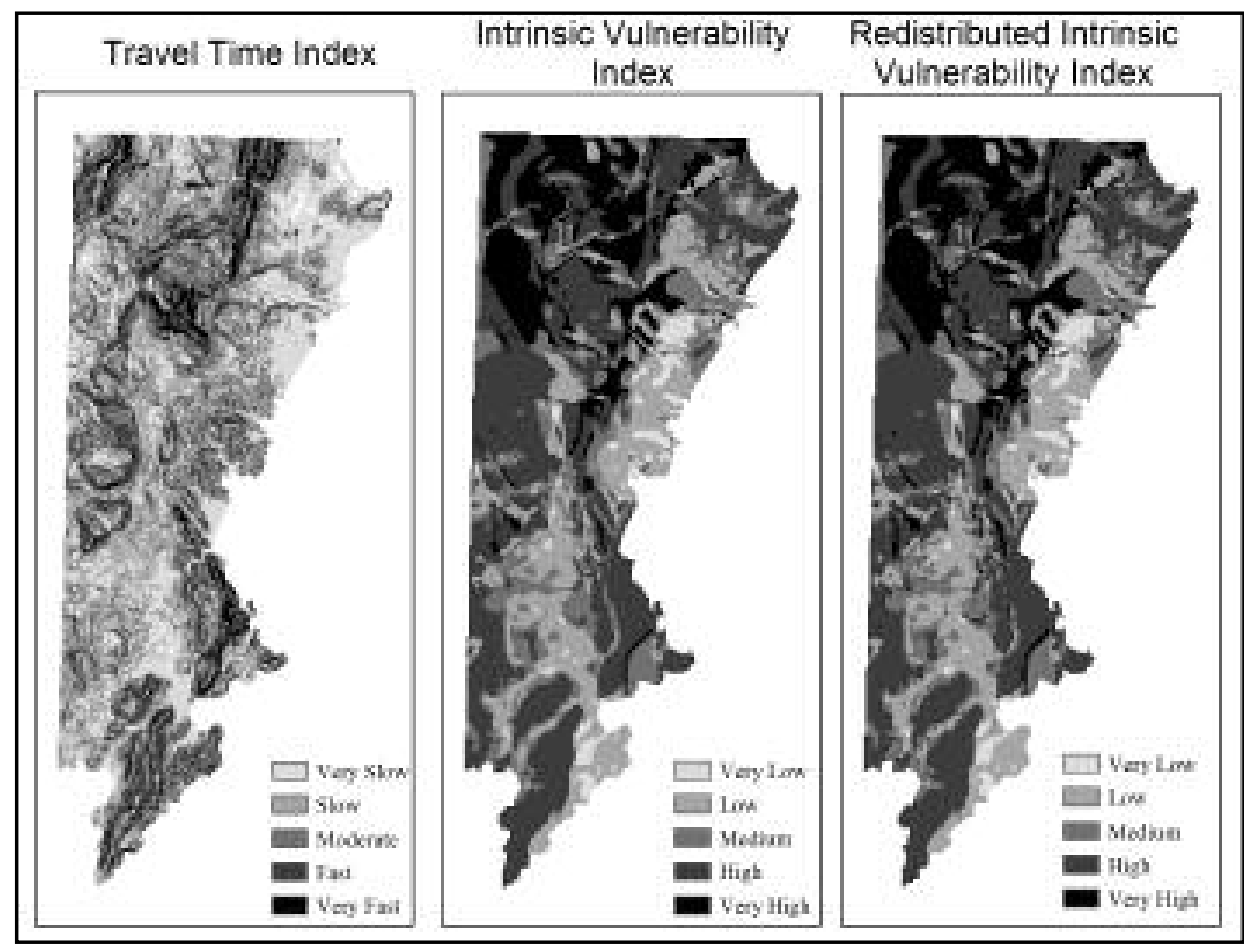

Fig. 5. Redistributed Intrinsic Vulnerability Values for the Olimpos National Park Area

\begin{tabular}{ll} 
RIVI Range & Area $\%$ \\
\hline Very High & 17.72 \\
High & 40.16 \\
Moderate & 18.74 \\
Low & 20.63 \\
Very Low & 2.75 \\
\hline
\end{tabular}

\section{Conclusions}

Various methods are suggested in the literature to assess groundwater pollution potential. Several of them are applied to non-karstic aquifers, where they give accurate results. Karst is considered in terms of lithology and hydraulic conductivity without taking into account its unique hydrological behavior, which in most cases underestimates the impact of the vadose zone in the commonly used methods such as DRASTIC or SINTACS. On the other hand, methods that were developed specifically for small-scale karst areas (like EPIK) are lacking a means for characterizing allogenic recharge. Meanwhile, the features considered in these kinds of methods (e.g.EPIK), such as the impact of epikarst and karst flow, are somewhat ambiguous and should be elaborated. Considering the fact that DRASTIC is the most efficient method in vulnerability mapping, and that most karstic 
areas in Turkey are surrounded by non-karstic units within the same hydrologic basin, DRASTIC was modified for areas including karst areas by stressing the specific hydrologic nature of karst. An index called the surface cover infiltration ability index (SCI) is defined to include the specific nature of karst. Surface lithology, lineaments, drainage density, and existence of karstic features are considered in the derivation of the SCI map. In the following step, the soil thickness is matched with the SCI layer to produce the surface cover protectiveness (SCP). Precipitation over the area is then evaluated together with SCI and soil cover to obtain the intrinsic vulnerability index values (IVI). However, this map does not take allogenic recharge into account and therefore requires an adjustment for it. The adjustment is achieved by redistributing the IVI values such that the IVI of areas that contribute to higher vulnerability areas are weighted according to their effects on the high- vulnerability (karst) areas to which they drain. The weighting is made on the basis of the time of concentration concept in hydrology. This parameter involves the distance and surface slope between two areas. Thus, the faster the contribution provided by the low IVI area, the higher weight is assigned to that area.

Although application of the method to a real area revealed that it is efficient, the features and parameters used require a fine calibration. Comparison of most commonly used methods in a well-known area would provide this calibration.

\section{Acknowledgements}

This study is based on the methodology developed for surface cover infiltration ability index in the framework of the project 'Resource Management in Karstic Areas of Coastal Regions of the Mediterranean Countries' supported by the European Commission with Contract No: ERBIC18CT970151. The authors extend their sincere thanks to Dr. Arthur N. Palmer for his invaluable contribution by his critics and comments on the paper.

\section{References}

Aller L., Bennett T., Lehr J. H., Petty R. J. \& Hackett G., 1987 - DRASTIC: A Standardized System For Evaluating Groundwater Potential Using Hydrogeologic Settings, US-EPA Report 600-2-87-035.

Bear J., 1979, Hydraulics of Groundwater, McGraw-Hill

Civita, M. Forti P., Marini P., Mecherri M. Micheli L. Piccini L. Pranzini G., 1991 - Pollution Vulnerability Map for the Aquifers of the Apuan Alps (Tuscani-Italy), National Research Council, Firenze.

Doerfliger N.\& Zwahlen F., 1995 - EPIK: A New Method for Outlining Protection Areas in Karst Environment. Proc. Of. The $5^{\text {th }}$. Int. Sym. \& Field Sem. on Karst Water and Environment. Antalya. Balkema.

Freeze R. A., \& Cherry, J. A., 1979 - Groundwater, Prentice-Hall. Kirpich Z. P., 1940 - Time of concentration of small agricultural watersheds, Civ. Eng., Vol 10, № 6, p. 362 